\title{
Study on Social Responsibility Reports of Listed Companies in China
}

\author{
Xing Liu \\ North China Electric Power University, Beijing, China \\ ncepu_Ix@163.com
}

Keywords: Listed company; Social responsibility; Stakeholder

\begin{abstract}
This thesis illustrates the necessity of the report on listed companies' fulfillment of social responsibilities through the description of the launch of China's listed companies social responsibilities disclosure rules and the companies' own demand for development; this concludes the basic prospect and trend of the development of reports on listed companies' social responsibilities in China through collections and analyses the statistics of changes in quantity of reports and industries as well as the companies' will to release their reports; this also gives some suggestions and measures for the improvement of the quality of enterprises' reports on social responsibilities from enterprises' and stakeholders' perspectives.
\end{abstract}

\section{The Necessity of Releasing Listed Companies' Social Responsibility Report}

Domestic Regulations and Rules. The continuous launch of relevant regulations gives great impetus to disclosing reports on social responsibilities. Released in September 2006, the Shenzhen Stock Exchange listed company social responsibility guidelines (hereinafter referred to as "guidelines") encourages the listed companies to establish the social responsibility system in accordance with the requirements of "guidance" and stick to the regular evaluation of the implementation of enterprises' social responsibility system and the existing problems so as to release social responsibility reports on a regular basis. "Guidance" issued by Shenzhen Stock Exchange has the milestone significance, marking the commencement of official guidance and regulation on listed companies' socially responsible activities in China. Although the "guidance" is not mandatory, it inevitably exerts impacts on companies listed in Shenzhen Stock Exchange. After that, the State-owned Assets Supervision and Administration Commission of the State Council issued in January 2008 the first "Guidelines on the Central Enterprises' Fulfillment of Social Responsibilities", and Shanghai Stock Exchange also issued in May 2008 "Notice on strengthening the fulfillment of listed companies' social responsibilities". These will help institutionalize the regular reports on listed companies' social responsibilities in our country.

The Demand of the Development of Enterprises. Table 1 In order to systematically summarize their own social responsibility practices, to help sort out the already-taken social responsibilities and their benefits and to show the value of responsibility information, enterprises release reports on social responsibility on a regular basis. This also helps enterprises get a thorough understanding of their own advantages and disadvantages, improve their strategic targets, accurately identify themselves in the market and build their own core competitiveness. By shouldering social responsibilities, enterprises establish fine company images, strengthen the communication with other companies, improve the relationship between enterprises and the whole society, promote innovation and create a favorable social surroundings for the sustainable development.

Companies can effectively interact with stakeholders by releasing social responsibility reports. (Stakeholders to those individuals or groups who are capable of influencing a company and are also affected by it, including shareholders, creditors, employees, suppliers, consumers, government departments, relevant non-governmental organizations and peripheral members of society (Cui Can, 2008)) Being the most effective way of communication with stakeholders, social responsibility reports are able to promote, maintain and constantly improve the involvements of the stakeholders. 
Table 1 Survey on the effects of China's enterprises' social responsibility reports

\begin{tabular}{|c|c|c|}
\hline Number & Export interview in 2013 & Export interview in 2014 \\
\hline 1 & Improve companies' images in society & Improve companies' images in society \\
\hline 2 & $\begin{array}{c}\text { Promote information exchange with the outside } \\
\text { world }\end{array}$ & $\begin{array}{c}\text { Promote information exchange with the } \\
\text { outside world }\end{array}$ \\
\hline 3 & $\begin{array}{c}\text { Stimulate companies to fulfill their social } \\
\text { responsibilities }\end{array}$ & $\begin{array}{c}\text { Stimulate companies to fulfill their social } \\
\text { responsibilities }\end{array}$ \\
\hline 4 & Attract foreign investment & Intensify ability of risk management \\
\hline 5 & Intensify ability of risk management & Improve management efficiency of enterprises \\
\hline 6 & Improve management efficiency of enterprises & Attract foreign investment \\
\hline 7 & Attract talented human resources & Attract talented human resources \\
\hline 8 & Attract talented human resources & Promote innovation in enterprises \\
\hline
\end{tabular}

Data sources: Syntao "Research on China's Sustainable Development Report 2013", "Research on China's Sustainable Development Report 2014".

\section{Statistics and Analyses}

\section{Report Total and Analysis of Boards.}

Table 2 Report quantities in different boards from 2012 to 2014

Units: [copy]

\begin{tabular}{|c|c|c|c|c|c|c|}
\hline \multirow{2}{*}{ Boards } & \multicolumn{2}{|c|}{2014} & \multicolumn{2}{c|}{2013} & \multicolumn{2}{c|}{2012} \\
\cline { 2 - 7 } & $\begin{array}{c}\text { Quantity of } \\
\text { releases }\end{array}$ & Percentage & $\begin{array}{c}\text { Quantity of } \\
\text { releases }\end{array}$ & Percentage & $\begin{array}{c}\text { Quantity of } \\
\text { releases }\end{array}$ & Percentage \\
\hline $\begin{array}{c}\text { Shanghai Stock Exchange } \\
\text { motherboard }\end{array}$ & 397 & $57.87 \%$ & 386 & $58.66 \%$ & 351 & $59.29 \%$ \\
\hline $\begin{array}{c}\text { Shenzhen Stock Exchange } \\
\text { motherboard }\end{array}$ & 124 & $18.08 \%$ & 119 & $18.09 \%$ & 123 & $20.78 \%$ \\
\hline $\begin{array}{c}\text { Small and medium-sized } \\
\text { board }\end{array}$ & 136 & $19.83 \%$ & 124 & $18.84 \%$ & 98 & $16.55 \%$ \\
\hline GEM & 29 & $4.23 \%$ & 29 & $4.41 \%$ & 20 & $3.38 \%$ \\
\hline Total & 686 & $100 \%$ & 658 & $100 \%$ & 592 & $100 \%$ \\
\hline
\end{tabular}

Table 3 Growing rate of release quantities in different boards from 2012 to 2014

\begin{tabular}{|c|c|c|c|c|c|c|}
\hline \multirow{2}{*}{ Boards } & \multicolumn{2}{|c|}{2014} & \multicolumn{2}{c|}{2013} & \multicolumn{2}{c|}{2012} \\
\cline { 2 - 8 } & $\begin{array}{c}\text { Quantity of } \\
\text { releases }\end{array}$ & $\begin{array}{c}\text { Growing } \\
\text { rate }\end{array}$ & $\begin{array}{c}\text { Quantity of } \\
\text { releases }\end{array}$ & $\begin{array}{c}\text { Growing } \\
\text { rate }\end{array}$ & $\begin{array}{c}\text { Quantity of } \\
\text { releases }\end{array}$ & $\begin{array}{c}\text { Growing } \\
\text { rate }\end{array}$ \\
\hline $\begin{array}{c}\text { Shanghai Stock Exchange } \\
\text { motherboard }\end{array}$ & 397 & $2.85 \%$ & 386 & $9.97 \%$ & 351 & $9.01 \%$ \\
\hline $\begin{array}{c}\text { Shenzhen Stock Exchange } \\
\text { motherboard }\end{array}$ & 124 & $4.20 \%$ & 119 & $-3.25 \%$ & 123 & $0.82 \%$ \\
\hline $\begin{array}{c}\text { Small and medium-sized } \\
\text { board }\end{array}$ & 136 & $9.68 \%$ & 124 & $26.53 \%$ & 98 & $34.25 \%$ \\
\hline GEM & 29 & $0.00 \%$ & 29 & $45.00 \%$ & 20 & $42.86 \%$ \\
\hline Total & 686 & $100 \%$ & 658 & $100 \%$ & 592 & $100 \%$ \\
\hline
\end{tabular}

Data sources: China's white paper on the listed company social responsibility report[1].

By April 30th, 2014, 674 of all A-share listed companies in China (hereinafter referred to as "listed company") had released social responsibility reports (including the social responsibility 
report, the sustainable development report, the corporate citizenship report, the environmental report). A total of 686 copies. This figure increased by $4.26 \%$ from 658 in 2013 with its growing rate plummeting from $11.15 \%$ [1].

According to the statistics from 2012 to 2014 of reports on social responsibility, $41.26 \%$ of all listed enterprises in Shanghai Stock Exchange had released their own social responsibility report. Reports released in Shanghai Stock Exchange motherboard had always accounted for more than half of all reports, leaving other boards far behind; Shenzhen Stock Exchange motherboard, small and medium-sized board and GEM had accounted for about 20\%,18\% and $4 \%$ respectively, remaining basically unchanged. The growing rate in Shanghai Stock Exchange motherboard, small and medium-sized board and GEM witnessed a significant decline in 2014, that in Shenzhen Stock Exchange motherboard up from $-3.25 \%$ in 2013 to $+4.20 \%$ in 2014, marking signs of a rebound.

However, despite the steady increase in release quantity, but the proportion of China's listed companies releasing social responsibility report is still in a relatively low level, with some companies even suspending their reports on social responsibility.

\section{Analysis of Changes in Industry Reports.}

Table 4 Industry growing rate in 2012 and 2013

\begin{tabular}{|c|c|c|c|c|}
\hline Industries & 2013 & 2012 & Growth quantity & Growing rate \\
\hline Manufacturing industry & 344 & 302 & 42 & $13.91 \%$ \\
\hline Transportation and warehousing industry & 38 & 39 & -1 & $-2.56 \%$ \\
\hline Banking and insurance industries & 40 & 39 & 1 & $2.56 \%$ \\
\hline IT industry & 40 & 36 & 4 & $11.11 \%$ \\
\hline Property and real estate industry & 40 & 34 & 6 & $17.65 \%$ \\
\hline Mining industry & 32 & 30 & 2 & $6.67 \%$ \\
\hline Electricity, gas and water production and supply industry & 28 & 27 & 1 & $3.70 \%$ \\
\hline Wholesale and retail trade & 29 & 26 & 3 & $11.54 \%$ \\
\hline others & 19 & 19 & 0 & $0.00 \%$ \\
\hline Construction industry & 20 & 16 & 4 & $25.00 \%$ \\
\hline Social services industry & 12 & 11 & 1 & $9.09 \%$ \\
\hline Agriculture, forestry, fishery and animal husbandary & 10 & 9 & 1 & $11.11 \%$ \\
\hline Dissemination and culture industry & 6 & 4 & 2 & $50.00 \%$ \\
\hline Total & 658 & 592 & 66 & $11.15 \%$ \\
\hline
\end{tabular}

Data sources: The WTO economy guide database [2]

Statistics witnessed an overall increase of industry reports in most industries. Of that, both release and increase quantity of reports issued by manufacturing enterprises took up more than 50\% of total. Manufacturing industry, real estate industry and IT industry and construction industry were top 3 industries in terms of quantity increase( the last two shared the third place),respectively up by 42, 6 and 4 copies. While in terms of growing rate culture industry, construction industry and manufacturing industry were leading three, respectively up by $50 \%, 25 \%$ and $13.91 \%$. We can find that industries faced with great responsibility risks, pollution and destruction disclosed more social responsibility reports than other industries, fully demonstrating listed companies' primary responses to social responsibility which is required by their stakeholders.

Besides, compared with most other industries, transportation and warehousing industry released less social responsibility reports than before. Apart from that listed companies which released social responsibility reports in accordance with provisions last year may suspend their release this year, there is a crying need for improvement in voluntary advocates, initiative actions in some industries and a sense of ownership of listed companies' stakeholders. 


\section{Analysis of Companies' Wills to Release.}

Table 5 Companies' wills to release social responsibility report in 2012 and 2013

\begin{tabular}{|c|c|c|c|c|}
\hline \multirow{2}{*}{} & \multicolumn{2}{|c|}{2012} & \multicolumn{2}{c|}{2013} \\
\cline { 2 - 5 } & Quantity & Percentage & Quantity & Percentage \\
\hline Voluntary & 189 & $32 \%$ & 247 & $38 \%$ \\
\hline Non-voluntary & 393 & $68 \%$ & 401 & $62 \%$ \\
\hline Total & 582 & $100 \%$ & 648 & $100 \%$ \\
\hline
\end{tabular}

Table 6 Listed companies' wills to release in different boards

\begin{tabular}{|c|c|c|c|}
\hline Boards & Total quantity & Quantity of voluntary report releases & Percentage \\
\hline Shanghai Stock Exchange motherboard & 382 & 81 & $21.20 \%$ \\
\hline Shenzhen Stock Exchange motherboard & 118 & 46 & $38.98 \%$ \\
\hline Small and medium-sized board & 120 & 93 & $77.50 \%$ \\
\hline GEM & 28 & 27 & $96.43 \%$ \\
\hline Total & 648 & 247 & $38.12 \%$ \\
\hline
\end{tabular}

By April 30, 2014, 648 listed companies had released 658 social responsibility reports. Of that, 401 companies did it in accordance with provisions, 247 voluntarily, taking up $38.12 \%$ of total. And that of last year was 189 , meaning this year witnessed a $30.7 \%$ year-on-year increase.

Through all quantities and proportions of voluntary release in different boards, only that in Shanghai Stock Exchange was below average level. Most companies in Shanghai Stock Exchange are state-owned and subject to "the guidance on fulfillment of social responsibility of state-owned enterprises" and most of them released reports by rules but not voluntarily. As a result, only $21.20 \%$ of all companies in Shanghai Stock Exchange in 2013 issued their social responsibility reports voluntarily. Table 6 shows us that in Shenzhen Stock Exchange motherboard, small and medium-sized board and GEM, there were respectively $38.98 \%, 77.50 \%$ and $96.43 \%$ of all companies voluntarily releasing their reports, all above average levels.

From 2013 to 2014, the policy of mandatory disclosure of listed companies' social responsibility report remained unchanged, but there were an increasing number of voluntary disclosures, which demonstrates the strengthening of enterprises' sense of social responsibility and a more positive attitude toward their responsibilities to their stakeholders. Social responsibility report has also gradually become an important part of an enterprise's non-financial information reports.

In conclusion, in 2014 the release quantity of China's listed company's social responsibility reports increased steadily, with reports' format more standard, content richer and information more complete. However, a point worth mentioning is that the listed companies still managed their social responsibility in a low level, which caused a lack of striking quality improvements in social responsibility reports. Only if China's listed companies further strengthen their sense of social responsibility and their managements of their own social responsibilities can they radically improve the quality of their reports and effectively communicate with stakeholders.

\section{Suggestions and Measures}

The development of enterprises' responsibility report are still in its early stages. There is still a need for the further improvement of the institutionalization, standardization and efficiency of the reports. As the makers, users and supervisors of social responsibility reports, enterprises, stakeholders and the government should strengthen their own sense of responsibility so as to give the full play to the values of enterprises' social responsibility report [4]. 
From Enterprises' Aspect. As makers of the report, the listed companies should release satisfactory social responsibility reports to demonstrate their responsibilities for stakeholders, which are based on their responsible practices. Enterprises can improve their practices and reports by doing these: (1) Give priority both to quality and to quantity of their social responsibility reports, improve the continuity, readability and ensure the credibility of them. (2) Voluntarily release their social responsibility reports and also carry out the independent third-party evaluations so as to guarantee the credibility of the reports. According to previous statistics, only a few companies were willing to release their social responsibility reports voluntarily. There is still a crying need for improvements of the credibility of the information disclosed in reports. Managers of listed companies should positively intensify auditing awareness. A third-party examination system need to be established to gradually replace the existing internal information examination system, to improve the verifiability and credibility of enterprises' social responsibility reports.

From Stakeholders' Aspect. As the users of social responsibility reports, stakeholders react to the information in these reports, and their reaction is the major indicator of the usability of a social responsibility report. At the same time, the involvement of stakeholders can somehow affect the decision-making process. The involvement of stakeholders can be improved by doing these: (1) We should intensify publicity, make the most of the existing mass media platforms to raise the public's awareness of social responsibility and strengthen their sense of ownership. Continuous efforts should be made to eventually foster a universal concept of social responsibility in the whole society. (2) Stakeholders should strengthen their sense of ownership and take an active part in the drafting and evaluating process of enterprises' social responsibility reports so as to improve enterprises' decision-making process, management and strategies with regard to social responsibility. This will meet their needs for more information and achieve a win-win situation.

From the Government's Aspect. As the supervisor of enterprises' social responsibility reports, the government and its relevant departments should fully play their important role of guidance and supervision so as to accelerate the development of domestic listed companies' social responsibility reports. Measures below can be taken by the government to accelerate the practice of listed companies' social responsibility reports in our country: (1) Promote the establishment of relevant laws and regulations, and guarantee laws' reliability and full implementation. Restrict and standardize enterprises' economic practices through laws. At present, although the domestic relevant laws and regulations such as "the rule of governance of listed companies", "the company law", "environmental protection law" and so on stipulate the performance of the social responsibility by enterprises, there are few regulations exclusively promulgated for the disclosure of enterprises' social responsibility information. To address this, the national legislature should speed up the establishment of relevant laws and regulations to standardize the disclosure of listed companies' social responsibility reports and eventually provide powerful legal support for regulators. (2) Combine the voluntary and mandatory ways of social responsibility report disclosure. By 2014, with evaded crucial points, insufficient content, poor readability and a lack of sense of social responsibility, most of the listed companies' disclosure of social responsibility report had been non-voluntary. The government must advocate the voluntary release of enterprises' social responsibility reports and give full play to this kind of reports through the severe enforcement of regulations.

\section{References}

[1] Economics Division of Chinese Academy of Social Sciences: Research report on the information disclosure of China's listed companies' social responsibility (2014), p.15 (Language: In Chinese).

[2] J.Zhao: Research on China's A-share listed companies' social responsibility reports (2012) (China WTO Tribune, 2013 (7)), p.36 (Language: In Chinese). 
[3] W. Zhang and Y. Zhang: Report on the information disclosure of China's listed companies' social responsibility (2013) [M], Social Sciences Academic Press, China, (2013) No.7 p.66.

[4] F.L.Zhang: Quality evaluation of China's listed companies' social responsibility reports [J], (Ms. Beijing Forestry University, China 2010), p.28 (Language: In Chinese). 